\title{
Differences in healthcare costs in youths with conduct disorders in rural vs. urban regions: an analysis of German health insurance data
}

\author{
Heike Gerhardt ${ }^{1}$, Monika Heinzel-Gutenbrunner ${ }^{1}$ and Christian J. Bachmann ${ }^{1,2^{*}}$ (D)
}

\begin{abstract}
Background: For children and adolescents with mental health problems, there is a lack of data as to whether the type of residential area (urban vs. rural) influences healthcare costs for affected individuals. The aim of this study was therefore to explore potential urban vs. rural healthcare cost differences in children and adolescents with conduct disorder (CD), one of the most frequent and cost-intensive child and adolescent psychiatric disorders. Additionally, we aimed to compare healthcare costs of youths with CD, and of youths without this diagnosis.
\end{abstract}

Methods: We analysed data from a German health insurance company, extracting all youths with a CD diagnosis in 2011 (CD group; $N=6337$ ), and an age- and sex-matched group without this diagnosis (control group). For both groups, annual costs per person for outpatient and inpatient healthcare were aggregated, stratified by area of residence (urban vs. rural).

Results: While mean annual overall costs in the CD group did not differ significantly between urban and rural areas of residence (2785 EUR vs. 3557 EUR, $p=0.253$ ), inpatient treatment costs were significantly higher in rural areas (2166 EUR (60.9\% of overall costs) vs. 1199 EUR (43.1\% of overall costs), $p<0.0005)$. For outpatient healthcare costs, the reverse effect was found, with significantly higher costs in individuals from urban areas of residence (901 EUR (32.3\% of overall costs) vs. 581 EUR (16.3\% of overall costs), $p<0.0005)$.

In the control group, no significant rural vs. urban difference was found for either overall health costs, inpatient or outpatient costs. Mean overall costs in the CD group were four times higher than in the control group (3162 ( \pm 5934$)$ EUR vs. 795 ( \pm 4425$)$ EUR).

Conclusions: This study is the first to demonstrate urban vs. rural differences in healthcare costs among youths with CD. The higher costs of inpatient treatment in rural regions may indicate a need for alternative forms of service provision and delivery in rural settings.

Keywords: Adolescents, Children, Conduct disorder, Cost analysis, Germany, Health insurance company, Rural, Secondary data, Health services utilisation, Urban

\footnotetext{
* Correspondence: christian.bachmann@|vr.de

'Department of Child and Adolescent Psychiatry, Philipps-University Marburg,

Hans-Sachs-Str. 4-6, DE-35039 Marburg, Germany

${ }^{2}$ Department of Child and Adolescent Psychiatry, LVR-Klinikum Düsseldorf/

Kliniken der Heinrich-Heine-Universität Düsseldorf, Bergische Landstraße 2,

DE-40629 Düsseldorf, Germany
}

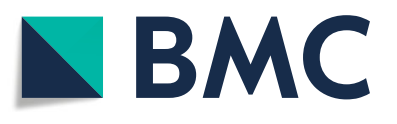

(c) The Author(s). 2018 Open Access This article is distributed under the terms of the Creative Commons Attribution 4.0 International License (http://creativecommons.org/licenses/by/4.0/), which permits unrestricted use, distribution, and reproduction in any medium, provided you give appropriate credit to the original author(s) and the source, provide a link to the Creative Commons license, and indicate if changes were made. The Creative Commons Public Domain Dedication waiver (http://creativecommons.org/publicdomain/zero/1.0/) applies to the data made available in this article, unless otherwise stated. 


\section{Background}

According to the International Classification of Diseases, 10th revision (ICD-10 [1]), conduct disorder and oppositional defiant disorders (within the following text summarised under the term "conduct disorders") can be defined as "a repetitive and persistent pattern of dissocial, aggressive or defiant conduct" that "violates the basic rights of others or age-appropriate societal expectations". Conduct disorders are among the most common disorders in child and adolescent psychiatry, with a prevalence of approximately $5-7 \%[2,3]$. In daily practice, children with conduct disorders constitute a significant portion of outpatients, e.g. $30 \%$ of a typical general practitioner's (GP) child consultations, and $45 \%$ of community child health referrals in the United Kingdom (UK) [4].

Psychiatric comorbidity in conduct disorders is common, and includes amongst others attention-deficit/ hyperactivity disorder (ADHD), depression, anxiety disorders, and substance misuse [5]. Without treatment, in up to $50 \%$ of individuals symptoms persist into adulthood, leading to antisocial personality disorder, criminal offending, or incarceration [6,7].

Studies from the UK and from Germany demonstrate an above-average healthcare utilisation and subsequent costs in individuals with conduct disorders [8-11].

In a British follow-up study, individuals diagnosed with conduct disorder in childhood had caused 8.8 times higher direct health costs in adulthood than same-aged individuals without childhood conduct disorder [10]. The same study provided estimates of lifetime costs for children with conduct disorder, which can amount to $\geq$ $£ 1$ million. In a German study, healthcare expenses for adolescents with conduct disorders were 3.8 times higher than in youth without a conduct disorder diagnosis [9].

Apart from health services utilisation, conduct disorder related costs are also incurred in the education system, within the family (through lost productivity), and - due to increased delinquency - in the justice system [11, 12]. Elevated levels of conduct problems in childhood are particularly associated with increased justice costs in adulthood [13]. A study of economic consequences of adolescent antisocial behaviour from the United States of America (USA) estimated additional costs at age 24 of 2.1-3.7 million USD for a typical criminal career [14]. Additionally, studies have demonstrated that even comorbid conduct disorder in children and adolescents with depression or ADHD doubled annual service use costs $[15,16]$.

While there is evidence that in adults with psychiatric disorders the type of residential area (urban vs. rural) significantly influences health service use and associated healthcare costs $[17,18])$, such data is not available for children and adolescents.
The few existing studies on urbanicity in relation to conduct disorders mainly focus on the influence of urban or rural environments on the prevalence of conduct disorders and antisocial behaviour: A study in US schoolchildren showed that while behaviour problems at home did not vary significantly across urban and rural settings, children in urban settings exhibited higher rates of school conduct problems [19]. Harden et al. studied 10- to 17-year olds in the UK, and did not find support for the hypothesis that living in densely populated counties influenced youth delinquency [20].

There is evidence that children and adolescents with conduct disorder frequently show complex and multiple service use patterns, e.g. primary healthcare, specialist child mental health services, emergency department visits, behavioural therapy, social services, contacts with the criminal justice system etc. [11, 21]. In rural areas, such a comprehensive array of services may not be as widely available as in urban areas [22-24]. In addition to the availability of services, factors like social visibility in small communities or difficulties associated with travelling to consult a mental health professional might also influence service use and associated healthcare costs in rural areas $[25,26]$.

This study therefore aimed to explore the following questions:

(1) Are there differences in overall, outpatient and inpatient healthcare costs in children and adolescents with a diagnosis of conduct disorder from urban vs. rural places of residence?

(2) Are there differences in the composition of healthcare costs in relation to type of cost and type of consulted medical specialty?

(3) Are there differences in overall, outpatient and inpatient healthcare costs in children and adolescents with a diagnosis of conduct disorder and of youths without this diagnosis?

\section{Methods \\ Data and sample}

This study used secondary data from the AOK Nordost health insurance company, which is a statutory health insurance company that covers about 1.8 million inhabitants of the German federal states Berlin, Mecklenburg-Western Pomerania and Brandenburg. Nearly $90 \%$ of children and adolescent in Germany are insured in a statutory health insurance company, whereas the remainder are privately insured [27]. Although there are several differences between the statutory and private system, both provide full-coverage health insurance. Insurees from a statutory health insurance company can go to almost any doctor or hospital 
in Germany in order to receive medical care, and have it reimbursed by their insurance company.

As compared with the entire German population, AOK insurees have a slightly lower socio-economic status, and more psychiatric morbidity [27].

Out of all children and adolescents who were insured in each quarter of 2011, we extracted all who were 5 to 18 years old in 2011, and for whom one of the following ICD-10 conduct disorder diagnoses had been documented: F90.1, F91.0, F91.1, F91.2, F91.3, F 91.8, F91.9, F92.0, F92.8 or F92.9. These children constituted the conduct disorder group. For the control group, a random sample of age-, sex-, and postcode-matched children without any of the afore-mentioned conduct disorder diagnoses in the years 2006-2011 was extracted from all AOK Nordost insurees in 2011.

For both groups, the prevalence of comorbid psychiatric diagnoses (remaining ICD-10 F codes) was evaluated.

Annual healthcare costs per individual for both groups were calculated by adding up the following cost data from the AOK data for the calendar year 2011: inpatient hospital costs, outpatient GP costs, outpatient specialist costs, prescription of pharmaceuticals, rehabilitation costs, costs for medical aids, and medical remedies, and reimbursement of healthcare-related travel expenses.

The variable "urban" vs. "rural" region was operationalised conferring to the number of inhabitants (urban: $\geq 100,000$ inhabitants, rural: <100,000 inhabitants), according to the definition of the German Federal Institute for Research on Building, Urban Affairs and Spatial Development (Bundesinstitut für Bau-, Stadt- und Raumforschung) [28].

\section{Statistical methods}

Because of the non-normal distribution of the data, Mann-Whitney tests were computed for the analysis of differences between health services utilisation costs in rural and urban regions. Additional dependent-samples analyses of variance were applied, based on the matched index-control pairs. This model enables the analysis of interactions between the conduct disorder group and the control group, and between urban and rural regions. In addition to $p$-values, effect sizes were calculated, based on the test statistics of the Mann-Whitney test.

\section{Results}

\section{Sample characteristics}

The conduct disorder group and the control group each consisted of 6337 individuals, $68.8 \%$ of which were male. The mean age was $11.2( \pm 3.7$, range: $5-18)$ years. In both groups, $43.2 \%$ of insurees were from the federal state of Berlin, $30.6 \%$ were from Brandenburg, and
26.1\% were from Mecklenburg-Western Pomerania. $51.2 \%$ were from an urban area of residence, and $48.8 \%$ lived in a rural area of residence. The proportion of individuals of non-German nationality was $26.2 \%$ in Berlin, $3.1 \%$ in Brandenburg, and 2.3\% in Mecklenburg-Western Pomerania.

In the conduct disorder group, $93.3 \%$ of urban residents, and $92.7 \%$ of rural residents had at least one psychiatric comorbidity $(p=0.348)$. In the control group, the corresponding prevalence rates were $24.0 \%$, and $25.8 \%$, respectively $(p=0.086)$.

\section{Cost analysis \\ Conduct disorder group}

The mean overall annual healthcare costs per person were $3162( \pm 5934)$ EUR, with overall healthcare costs not differing significantly between patients from urban and from rural regions (2785 EUR vs. 3557 EUR, $p=0.253$ ).

The detailed composition of costs by type of healthcare cost and area of residence (rural vs. urban) is shown in Table 1. Both in rural and urban areas, inpatient costs constituted the largest part of overall costs, followed by outpatient costs, and expenses for pharmacotherapy. Inpatient healthcare costs in rural regions of residence were significantly higher than those in urban areas, while outpatient healthcare costs were significantly higher in urban regions of residence.

Data on outpatient healthcare costs by type of physician (general practitioners and selected specialties) are presented in Table 2 . The highest outpatient costs were incurred by contacts with specialist doctors, i.e. child and adolescent psychiatrists, and paediatricians. Costs per specialty were significantly higher in insurees from urban areas of residence than in those from rural areas, while costs for GP consultations were significantly higher in rural areas.

\section{Control group}

In the control group, overall healthcare costs per person were $795( \pm 4425)$ EUR. Overall costs did not show a significant difference between urban and rural areas of residence (774 EUR vs. 817 EUR, $p=0.698$ ) (Table 1).

In rural areas, inpatient costs constituted the largest part of overall costs (35.5\%), while in urban areas costs for outpatient healthcare were the most important cost type $(29.7 \%)$. Costs for inpatient treatment in rural regions of residence were significantly higher than those in urban areas. For outpatient healthcare costs, this relationship was inverse.

Visits to paediatricians incurred the largest part of outpatient costs (Table 2). In urban areas, costs for specialist doctor consultations were significantly higher than in 


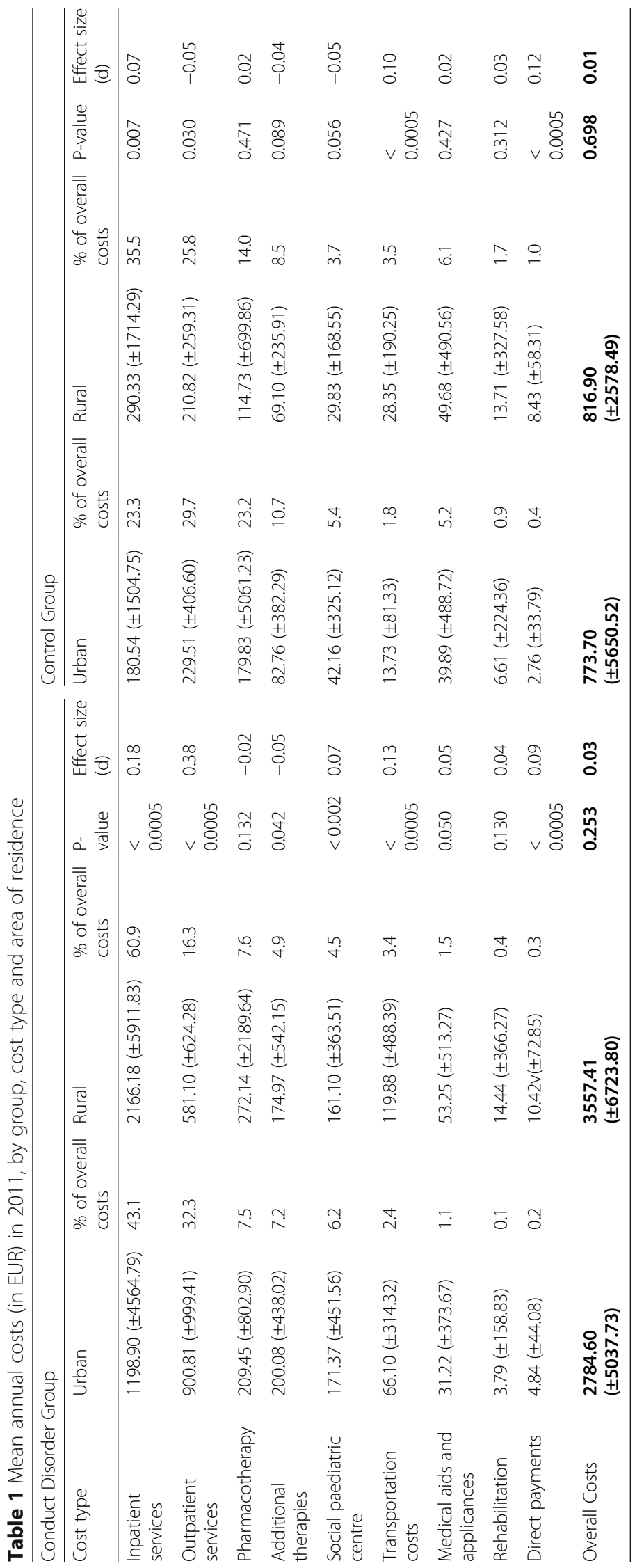


Table 2 Mean annual costs (in EUR) in 2011 for outpatient health services, by group and specialty

\begin{tabular}{|c|c|c|c|c|c|c|c|c|}
\hline \multirow[b]{2}{*}{ Specialty } & \multicolumn{4}{|c|}{ Conduct Disorder Group } & \multicolumn{4}{|l|}{ Control Group } \\
\hline & Urban & Rural & $P$-value & Effect size $(d)$ & Urban & Rural & $P$-value & Effect size $(\mathrm{d})$ \\
\hline $\begin{array}{l}\text { Child and adolescent } \\
\text { psychiatrist/ psychotherapist }\end{array}$ & $493.92( \pm 899.50)$ & $271.80( \pm 523.67)$ & $<0.0005$ & 0.23 & $31.28( \pm 235.10)$ & $20.56( \pm 155.65)$ & 0.033 & -0.05 \\
\hline Paediatrician & $165.92( \pm 233.14)$ & $95.64( \pm 135.60)$ & $<0.005$ & 0.24 & $83.85( \pm 114.64)$ & $69.61( \pm 92,96)$ & $<0.0005$ & -0.14 \\
\hline General practitioner & $48.55( \pm 87.57)$ & $57.83( \pm 79.86)$ & $<0.0005$ & 0.15 & $33.90( \pm 59.09)$ & $43.71( \pm 65.74)$ & $<0.0005$ & 0.16 \\
\hline
\end{tabular}

rural areas, and in rural areas, GP costs were significantly higher than in urban areas of residence.

In comparison, the mean annual overall healthcare costs per person in the conduct disorder group were 3.98-fold higher than those in the control group. With regard to inpatient healthcare, costs in the conduct disorder group were 6.64-fold (urban) and 7.46-fold higher (rural), respectively, than in the control group.

\section{Discussion}

The main finding of this exploratory study is the inverse relationship between inpatient and outpatient costs in the conduct disorder group: While inpatient costs were significantly higher in individuals from rural areas, outpatient costs were significantly higher in individuals from urban areas of residence.

A possible cause for these cost differences is an unequal availability of medical resources in urban vs. rural areas of residence. In Germany, there are considerable differences between rural and urban areas of residence in regard to the number and density of statutory health insurance-accredited physicians and mental health professionals. In 2011, for example, the most densely populated German federal state of Berlin (about 3950 inhabitants $/ \mathrm{km}^{2}$ ) had the highest density of registered psychotherapists of all federal states (60.3 per 100,000 inhabitants). In contrast, the two least populated, rural federal states Brandenburg and Mecklenburg-Western Pomerania (about 70-80 inhabitants $/ \mathrm{km}^{2}$ ) had a ratio of 12.5 and 10.9 psychotherapists per 100,000 inhabitants, respectively [29]. This urban vs. rural difference also applies to child and adolescent psychiatrist density: With the national average index set at 1 , the index for Berlin is 2.0, while for Brandenburg and Mecklenburg-Western Pomerania indices are $<1$, i.e. below the national average [30].

The above-mentioned differences in the availability of mental health professionals might have influenced service utilisation in the following way: In rural regions with a scarcity of office-based child and adolescent psychiatrists, cases where child and adolescent psychiatric diagnostic or therapeutic expertise is indispensable, are directly referred into hospital for further work-up, thus causing much higher inpatient treatment costs. The high costs for inpatient treatment (which constitute the largest part of conduct disorder treatment costs) are especially remarkable as there is no good evidence for lasting effects of inpatient treatment for children and adolescents with conduct disorders [2]. Vice versa, in urban areas of residence with a generally good availability of office-based child and adolescent psychiatrists, utilisation of these outpatient services is much higher than in rural regions, resulting in higher total outpatient costs, and - as timely intervention in an outpatient setting can often prevent inpatient admission - in lower inpatient costs. Higher utilisation of specialist physicians by insurees from urban areas in the presence of mental illness, together with higher associated healthcare costs, was confirmed in a recent study from Germany [31].

Yet, an Australian study focusing on mental health services use for anxiety and mood disorders in the general population did not find rural residence itself to be a limiting factor for access to mental health services. Instead, other factors, including education and distress, were more important predictors of mental health services utilisation [32].

Another possible explanation for the differences in inpatient and outpatient healthcare costs found in this study could be an urban vs. rural difference in terms of symptom severity or psychiatric comorbidity. Regarding symptom severity, this parameter was not included in the secondary data underlying this study, thus precluding such an analysis. Concerning psychiatric comorbidity, there were no significant urban vs. rural differences in the respective prevalence rates, which makes an influence of comorbidity on cost differences unlikely.

Concerning the distribution of costs according to service type, our results correspond with an economic analysis of adolescents with conduct disorder by Ewest et al. [9], with inpatient treatment costs being higher than outpatient treatment costs, and these being followed by costs for medication. Our findings in terms of cost distribution also comply with those of Kohlboeck et al. [33], who investigated child behavioural problems in Germany. However, their evaluation of behavioural problems was not based on any ICD-10 diagnosis, but rather on information provided by parents and their evaluation of their child's utilisation of healthcare services (outpatient and inpatient treatment). In their study, 
the severity of reported behavioural problems (abnormal vs. normal) correlated with about five-fold higher direct total costs for medical care, with hospital costs surmounting costs for outpatient physician visits.

Regarding the composition of outpatient costs, consultations of child and adolescent psychiatrist consultations naturally yielded the highest costs in the conduct disorder group. Regarding the higher costs for GP consultations in rural areas, these results are in agreement with a recent study demonstrating that children and young people in rural German areas use outpatient general medical care to a greater extent than those in urban areas [34], but also with studies of service use for mental health problems in rural areas in general [35].

In terms of the four times higher overall healthcare costs for children and adolescents with conduct disorders, our data is in line with the study by Ewest et al. [9], who found 3.8 times higher total annual costs for health services utilisation in the conduct disorder group compared to a control group. The even higher ratio in inpatient healthcare costs supports the notion of conduct disorder as a disorder that is difficult to treat within an outpatient setting [36].

Beyond the above-mentioned studies, there are currently no other comparable studies available which focus on urban vs. rural differences in the utilisation of healthcare services and health insurance expenses in youth with psychiatric disorders. Interestingly, our results largely comply with those of the few studies performed on rural vs. urban cost differences in adult psychiatric patients. These studies also did not find rural vs. urban differences in overall healthcare costs [18], and reported lower psychiatric outpatient service use in rural areas [17, 37], and higher inpatient costs in rural areas of residence [18].

While Tiainen et al. [37] and Ziller et al. [17] described higher utilisation of pharmacotherapy in rural areas, this finding could not be replicated in our study. The reason for this discrepancy is probably the fact that according to the guidelines for the management of conduct disorders in children and adolescents [4, 38], pharmacotherapy is not a recommended first-line treatment.

Drawing on our data, an improved healthcare provision for conduct disordered children and adolescents appears to be necessary primarily in rural areas. Given the scarcity of mental health professionals in these areas, improvements in healthcare provision for conduct-disordered youths should focus on dissemination and implementation of evidence-based prevention and intervention programmes [4] that do not draw on medical workforce capacity. A number of parenting programmes meet these criteria, e.g. the 12-week Incredible Years programme or the 8 -week Triple $P$ programme, which do not only improve conduct disorder symptoms, but have also proven to be cost-effective [39-42]. Another well-evaluated intervention is the home-based Multisystemic Therapy [43], which has demonstrated superiority over inpatient treatment, both clinically and in terms of cost-effectiveness, [44], and can be run by social workers.

An alternative would be the provision of distance- or internet-based interventions, for whose effectiveness there is a growing body of evidence $[45,46]$.

Beyond the reduction of healthcare costs, an improved provision of healthcare as delineated above would also have the potential for reducing non-medical costs associated with conduct disorders (e.g. youth welfare measures, special needs schooling, etc.) [13, 42, 47, 48], and, last but not least, reducing the higher mortality in rural areas.

\section{Strengths and limitations}

In terms of limitations, it is important to note that we used secondary data, so no external validation of the conduct disorder diagnoses was possible. Also, the data did not contain information on clinical factors potentially influencing service utilisation and associated costs, e.g. symptom severity $[10,13])$. Moreover, the underlying data stems from a single statutory health insurance fund, whose insurees have a slightly lower-than-average socioeconomic status, and an elevated level of mental health problems [27]. Thus, our sample is not representative for the whole of the German population, and may have incurred higher healthcare costs than insurees of other health insurance companies. Information on important confounders, e.g. education or family composition, was not available in the underlying secondary data set [49]. Also, our data does not include information regarding the utilisation of non-medical mental health care, e.g. parent training provided by social services.

In order to match control group and index group, not only age and sex but also the residential area (postcode) was taken into account, in order to serve as a proxy for socioeconomic status. Nevertheless, the lack of individual socioeconomic status data is a significant limitation, which should be mended in future studies, as some studies have demonstrated associations between socioeconomic status and health services use in children, albeit in different directions $[50,51]$. Moreover, the utilisation of healthcare services can also be influenced by nationality and ethnicity [52]. Unfortunately, the nationality data provided by the AOK Nordost does not always reflect the original ethnicity, thus precluding further analyses.

Another methodological issue is the definition of areas as urban and rural, with towns with more than 100,000 inhabitants being defined as urban. It is debatable whether this classification is appropriate in the case of Berlin, which simultaneously constitutes a city and a 
federal state. However, the afore-mentioned classification has also been employed within the German KiGGS study, a representative epidemiological study on child health [53], so we adhered to it for the sake of general comparability.

Additionally, it has to be noted that in Germany the unit costs for inpatient and outpatient treatment do not reflect the real costs of the service providers, but are rather a price negotiated between the health insurance company and the service providers.

Finally, it should be kept in mind that the effect sizes corresponding with the respective significant differences from our analysis are all small in dimension, thus qualifying the urban vs. rural differences.

A strength of this study is its use of administrative data, which allows to study real-world utilization patterns in a large and unselected population without nonresponse or recall bias problems. Moreover, this study is of special interest, as it constitutes the first approach to investigate rural vs. urban differences in the provision of healthcare for children and adolescents with conduct disorders.

\section{Conclusions}

This study is the first to demonstrate urban vs. rural differences in healthcare utilisation and costs among youths with conduct disorder. The higher costs of inpatient treatment in rural regions may indicate a need for alternative forms of service provision and delivery in rural settings.

\section{Abbreviations \\ ADHD: Attention-deficit/hyperactivity disorder; CD: Conduct disorder; GP: General practitioner; ICD-10: International Classification of Diseases, 10th revision; UK: United Kingdom; US/USA: United States of America}

\section{Acknowledgements}

We thank the AOK Nordost, particularly Dipl.-Inf. Volker Wenning, for extracting and providing the crude data for the study.

\section{Funding}

This research received no specific grant from any funding agency in the public, commercial, or not-for-profit sectors.

\section{Availability of data and materials}

The data that support the findings of this study are available from AOK Nordost, but restrictions apply to the availability of these data, which were used under license for the current study, and so are not publicly available. Data are however available from the authors upon reasonable request and with permission of AOK Nordost.

\section{Authors' contributions}

HG, MHG and CJB analysed and interpreted the data. CJB and HG wrote the manuscript. All authors read and approved the final manuscript.

\section{Ethics approval and consent to participate}

In accordance with German legal regulations (§15 MBO-Ä), an ethics approval was not required for this study, as only routinely collected anonymised secondary data was analysed.

Consent for publication

Not applicable.

\section{Competing interests}

The authors declare that they have no competing interests.

\section{Publisher's Note}

Springer Nature remains neutral with regard to jurisdictional claims in published maps and institutional affiliations.

Received: 20 April 2018 Accepted: 3 September 2018

Published online: 14 September 2018

\section{References}

1. Remschmidt H, Schmidt M, Poustka F. Multiaxiales Klassifikationsschema für psychische Störungen des Kindes- und Jugendalters nach ICD-10 und DSMIV. 4. vollständig überarbeitete und erweiterte Auflage edn. Bern; Göttingen; Toronto; Seattle: Huber; 2001.

2. Scott S. Oppositional and conduct disorders. In: Thapar A, Pine DS, Leckman JF, Scott S, Snowling MJ, Taylor E, editors. Rutter's Child and Adolescent Psychiatry. 6 edition. Chichester: Wiley Blackwell; 2015. p. 913-30.

3. Green H, McGinnity A, Meltzer H, Ford T, Goodman R. Mental health of children and young people in Great Britain, 2004. London: Office for National Statistics; 2005.

4. Pilling S, Gould N, Whittington C, Taylor C, Scott S. Recognition, intervention, and management of antisocial behaviour and conduct disorders in children and young people: summary of NICE-SCIE guidance. BMJ. 2013;346:f1298.

5. Maughan B, Rowe R, Messer J, Goodman R, Meltzer H. Conduct disorder and oppositional defiant disorder in a national sample: developmental epidemiology. J Child Psychol Psychiatry. 2004;45:609-21.

6. Moffitt T. Life-course-persistent versus adolescence-limited antisocial behaviour. Hoboken: Wiley; 2008.

7. Erskine HE, Norman RE, Ferrari AJ, Chan GCK, Copeland WE, Whiteford HA Scott JG. Long-term outcomes of attention-deficit/hyperactivity disorder and conduct disorder: a systematic review and meta-analysis. J Am Acad Child Adolesc Psychiatry. 2016;55:841-50.

8. Vostanis P, Meltzer H, Goodman R, Ford T. Service utilisation by children with conduct disorders-findings from the GB National Study. Eur Child Adolesc Psychiatry. 2003:12:231-8.

9. Ewest F, Reinhold T, Vloet TD, Wenning V, Bachmann CJ. Health insurance expenses caused by adolescents with a diagnosis of conduct disorder. Kindheit und Entwicklung. 2013;22:41-7.

10. Scott S, Knapp M, Henderson J, Maughan B. Financial cost of social exclusion: follow up study of antisocial children into adulthood. BMJ. 2001; 323:191.

11. Rivenbark JG, Odgers CL, Caspi A, Harrington H, Hogan S, Houts RM, Poulton MTE. The high societal costs of childhood conduct problems: evidence from administrative records up to age 38 in a longitudinal birth cohort. J Child Psychol Psychiatry. 2018:59:703-10.

12. Beecham J. Annual research review: child and adolescent mental health interventions: a review of progress in economic studies across different disorders. J Child Psychol Psychiatry. 2014;55:714-32.

13. D'Amico F, Knapp M, Beecham J, Sandberg S, Taylor E, Sayal K. Use of services and associated costs for young adults with childhood hyperactivity/ conduct problems: 20-year follow-up. Br J Psychiatry. 2014;204:441-7.

14. Cohen MA, Piquero AR. New evidence on the monetary value of saving a high risk youth. J Quant Criminol. 2009;25:25-49.

15. Knapp M, McCrone P, Fombonne E, Beecham J, Wostear G. The Maudsley long-term follow-up of child and adolescent depression: 3. Impact of comorbid conduct disorder on service use and costs in adulthood. Br J Psychiatry. 2002:180:19-23.

16. Jones DE, Foster EM. Service use patterns for adolescents with ADHD and comorbid conduct disorder. J Behav Health Serv Res. 2009;36:436-49.

17. Ziller EC, Anderson NJ, Coburn AF. Access to rural mental health services: service use and out-of-pocket costs. J Rural Health. 2010;26:214-24.

18. Nietert PJ, French MT, Kirchner J, Han X, Booth BM. Health services utilization and cost for at-risk drinkers: rural and urban comparisons. J Stud Alcohol. 2004;65:353-62.

19. Hope TL, Bierman KL. Patterns of home and school behavior problems in rural and urban settings. J Sch Psychol. 1998;36:45-58.

20. Harden KP, D'Onofrio BM, Van Hulle C, Turkheimer E, Rodgers JL, Waldman ID, Lahey BB. Population density and youth antisocial behavior. J Child Psychol Psychiatry. 2009;50:999-1008. 
21. Shivram R, Bankart J, Meltzer H, Ford T, Vostanis P, Goodman R. Service utilization by children with conduct disorders: findings from the 2004 Great Britain child mental health survey. Eur Child Adolesce Psychiatry. 2009;18: 555-63.

22. Cummings JR, Case BG, Ji X, Marcus SC. Availability of youth Services in U.S. mental health treatment facilities. Admin Pol Ment Health. 2016:43:717-27.

23. Anderson RL, Gittler J. Unmet need for community-based mental health and substance use treatment among rural adolescents. Community Ment Health J. 2005;41:35-49.

24. Bramesfeld A, Grobe T, Schwartz FW. Who is treated, and how, for depression? An analysis of statutory health insurance data in Germany. Soc Psychiatry Psychiatr Epidemiol. 2007:42:740-6.

25. Aisbett DL, Boyd CP, Francis KJ, Newnham K, Newnham K. Understanding barriers to mental health service utilization for adolescents in rural Australia. Rural Remote Health. 2007:7:624.

26. Boyd CP, Hayes L, Nurse S, Aisbett DL, Francis K, Newnham K, Sewell J. Preferences and intention of rural adolescents toward seeking help for mental health problems. Rural Remote Health. 2011;11:1582.

27. Hoffmann F, Bachmann CJ. Differences in sociodemographic characteristics, health, and health service use of children and adolescents according to their health insurance funds. BundesgesundheitsblattGesundheitsforschung-Gesundheitsschutz. 2014;57:455-63.

28. Laufende Stadtbeobachtung - Raumabgrenzungen. Stadt- und Gemeindetypen in Deutschland. [https://www.bbsr.bund.de/BBSR/DE/ Raumbeobachtung/Raumabgrenzungen/StadtGemeindetyp/ StadtGemeindetyp_node.html]. Accessed 10 Sept 2018.

29. Versorgungsatlas. Vertragsärzte und -psychotherapeuten je 100.000 Einwohner 2010 bis 2012 (nach Arztgruppen) [https://www. versorgungsatlas.de/themen/versorgungsstrukturen/?tab=6\&uid=20]. Accessed 10 Sept 2018.

30. Psychische Versorgung von Kindern und Jugendlichen - Kinder- und Jugendpsychiater und -psychotherapeuten [https://www.bertelsmann-stiftung. de/fileadmin/files/BSt/Publikationen/GrauePublikationen/GP_Faktencheck_ Gesundheit_Regionale_Unterschiede.pdf]. Accessed 10 Sept 2018.

31. Mehring M, Donnachie E, Schneider A, Tauscher M, Gerlach R, Storr C, Linde $\mathrm{K}$, Mielck A, Maier $\mathrm{W}$. Impact of regional socioeconomic variation on coordination and cost of ambulatory care: investigation of claims data from Bavaria, Germany. BMJ Open. 2017;7:e016218.

32. Hardy CL, Kelly KD, Voaklander D. Does rural residence limit access to mental health services? Rural Remote Health. 2011;11:1766.

33. Kohlboeck G, Romanos M, Teuner CM, Holle R, Tiesler CM, Hoffmann B, Schaaf B, Lehmann I, Herbarth O, Koletzko S, et al. Healthcare use and costs associated with children's behavior problems. Eur Child Adolesc Psychiatry. 2014;23:701-14.

34. Wölfle $S$, Jost D, Oades R, Schlack R, Hölling H, Hebebrand J. Somatic and mental health service use of children and adolescents in Germany (KiGGSstudy). Eur Child Adolesc Psychiatry. 2014;23:753-64

35. Perkins D, Fuller J, Kelly BJ, Lewin TJ, Fitzgerald M, Coleman C, Inder KJ, Allan J, Arya D, Roberts R, Buss R. Factors associated with reported service use for mental health problems by residents of rural and remote communities: cross-sectional findings from a baseline survey. BMC Health Serv Res. 2013;13:157.

36. Bachmann M, Bachmann CJ, John K, Heinzel-Gutenbrunner M, Remschmidt $H$, Mattejat F. The effectiveness of child and adolescent psychiatric treatments in a naturalistic outpatient setting. World Psychiatry. 2010;9:111-7.

37. Tiainen A, Edman G, Flyckt L, Tomson G, Rehnberg C. Regional variations and determinants of direct psychiatric costs in Sweden. Scand J Public Health. 2008;36:483-92.

38. Deutsche Gesellschaft für Kinder- und Jugendpsychiatrie und Psychotherapie (DGKJP): Leitlinien zu Diagnostik und Therapie von psychischen Störungen im Säuglings-, Kindes- und Jugendalter. 3rd edn Cologne: Deutscher Ärzteverlag; 2007.

39. Sampaio F, Barendregt JJ, Feldman I, Lee YY, Sawyer MG, Dadds MR, Scott $J G$, Mihalopoulos C. Population cost-effectiveness of the triple P parenting programme for the treatment of conduct disorder: an economic modelling study. Eur Child Adolesc Psychiatry. 2017;27:933-44.

40. Presnall N, Webster-Stratton CH, Constantino JN. Parent training: equivalent improvement in externalizing behavior for children with and without familial risk. J Am Acad Child Adolesc Psychiatry. 2014;53:879-87.
41. Sanders MR, Kirby JN, Tellegen CL, Day JJ. The triple P-positive parenting program: a systematic review and meta-analysis of a multi-level system of parenting support. Clin Psychol Rev. 2014;34:337-57.

42. Edwards RT, Ceilleachair A, Bywater T, Hughes DA, Hutchings J. Parenting programme for parents of children at risk of developing conduct disorder: cost effectiveness analysis. BMJ. 2007;334:682.

43. Butler S, Baruch G, Hickey N, Fonagy P. A randomized controlled trial of multisystemic therapy and a statutory therapeutic intervention for young offenders. J Am Acad Child Adolesc Psychiatry. 2011;50:1220-1235.e1222.

44. Henggeler SW, Rowland MD, Randall J, Ward DM, Pickrel SG, Cunningham PB, Miller SL, Edwards J, Zealberg JJ, Hand LD, Santos AB. Home-based multisystemic therapy as an alternative to the hospitalization of youths in psychiatric crisis: clinical outcomes. J Am Acad Child Adolesc Psychiatry. 1999;38:1331-9.

45. Reid GJ, Stewart M, Vingilis E, Dozois DJ, Wetmore S, Jordan J, Dickie G, Osmun WE, Wade TJ, Brown JB, Zaric GS. Randomized trial of distancebased treatment for young children with discipline problems seen in primary health care. Fam Pract. 2013;30:14-24.

46. Sourander A, McGrath PJ, Ristkari T, Cunningham C, Huttunen J, Lingley-Pottie P, Hinkka-Yli-Salomaki S, Kinnunen M, Vuorio J, Sinokki A, et al. Internet-assisted parent training intervention for disruptive behavior in 4-year-old children: a randomized clinical trial. JAMA Psychiatry. 2016;73:378-87.

47. Bonin EM, Stevens M, Beecham J, Byford S, Parsonage M. Costs and longerterm savings of parenting programmes for the prevention of persistent conduct disorder: a modelling study. BMC Public Health. 2011;11:803.

48. Scott S, Briskman J, O'Connor TG. Early prevention of antisocial personality: long-term follow-up of two randomized controlled trials comparing indicated and selective approaches. Am J Psychiatry. 2014;171:649-57.

49. Curtis S, Pain R, Fuller S, Khatib Y, Rothon C, Stansfeld SA, Daya S. Neighbourhood risk factors for common mental disorders among young people aged 10-20 years: a structured review of quantitative research. Health Place. 2013:20:81-90.

50. Mandell DS, Novak MM, Zubritsky CD. Factors associated with age of diagnosis among children with autism spectrum disorders. Pediatrics. 2005; 116:1480-6

51. van der Linden J, Drukker M, Gunther N, Feron F, van Os J. Children's mental health service use, neighbourhood socioeconomic deprivation, and social capital. Soc Psychiatry Psychiatr Epidemiol. 2003;38:507-14.

52. Mendenhall AN, Demeter C, Findling RL, Frazier TW, Fristad MA, Youngstrom EA, Arnold LE, Birmaher B, Gill MK, Axelson D, et al. Mental health service use by children with serious emotional and behavioral disturbance: results from the LAMS study. Psychiatr Serv. 2011;62:650-8.

53. Rattay P, Starker A, Domanska O, Butschalowsky H, Gutsche J, Kamtsiuris P. Trends in the utilization of outpatient medical care in childhood and adolescence: results of the KiGGS study - a comparison of baseline and first follow up (KiGGS wave 1). Bundesgesundheitsblatt Gesundheitsforschung Gesundheitsschutz. 2014;57:878-91.

Ready to submit your research? Choose BMC and benefit from:

- fast, convenient online submission

- thorough peer review by experienced researchers in your field

- rapid publication on acceptance

- support for research data, including large and complex data types

- gold Open Access which fosters wider collaboration and increased citations

- maximum visibility for your research: over $100 \mathrm{M}$ website views per year

At BMC, research is always in progress.

Learn more biomedcentral.com/submissions 